\title{
LETRAMENTO: UMA DISCUSSÃO SOBRE IMPLICAÇÕES DE FRONTEIRAS CONCEITUAIS
}

\author{
Mary Elizabeth Cerutti-Rizzatti*
}

\begin{abstract}
RESUMO: Este artigo topicaliza um desconforto decorrente de alargamentos e circunscrições das fronteiras do conceito de letramento e defende que ambos os comportamentos incidem sobre a relevância conceitual do neologismo, tanto quanto têm implicações complexas no universo educacional. Esta abordagem contém a defesa do seguinte ponto de vista: a escrita é um processo com contornos socioculturais e econômicos de apropriação naturalística, contornos aos quais o fenômeno do letramento é sensível. Em se tratando das controversas relações entre letramento e alfabetização, defende-se a concepção de letramento como continente, tendo a alfabetização como um de seus conteúdos, o que não legitima sobreposições entre ambos os fenômenos nem tampouco expressões como alfabetização para o/com letramento.
\end{abstract}

Palavras-chave: Língua escrita. Letramento. Alfabetização.

\section{LITERACY: A DISCUSSION ABOUT IMPLICATIONS OF CONCEPTUAL BOUNDARIES}

ABSTRACT: The topic of this article derives from a discomfort caused by broadening and restrictions of the edges of the concept of literacy, and supports that both behaviors affect the conceptual relevance of the neologism, and have complex implications to the educational environment. This paper adopts the following point of view: writing is a process with sociocultural and economic delineation of naturalistic appropriation from which literacy is sensitive. Taking into account the controversial relationship between literacy and teaching/learning of reading and writing, it is claimed the concept of literacy as continent, considering teaching/learning of reading and writing as one of its contents, a view that neither legitimate overlapping between both phenomena nor expressions such as teaching/learning of reading and writing to/with literacy.

Key words: Writing. Literacy. Teaching/learning of reading and writing.

* Doutora em Letras e professora adjunta do Departamento de Língua e Literaturas Vernáculas da Universidade Federal de Santa Catarina (UFSC). E-mail: maryeli@intercorp.com.br 


\title{
LITÉRACIE: UNE DISCUSSION SUR LES IMPLICATIONS DE FRONTIÈRES CONCEPTUELLES
}

\begin{abstract}
RÉSUMÉ: Cet article traite d'un embarras qui provient d'élargissements et de circonscriptions des frontières du concept de litéracie et défend que ces deux comportements ont une incidence sur la pertinence conceptuelle du néologisme, tout comme ils ont des implications complexes dans l'univers éducationnel. Cette approche contient la défense du point de vue suivant: l'écriture est un processus ayant des contours socio-culturels et économiques d'appropriation naturalistique, contours auxquels le phénomène de litéracie est sensible. Quant aux controversées relations entre litéracie et alphabétisation, l'article défend la conception de litéracie comme contenant, l'alphabétisation étant comme un de ses contenus, ce qui ne permet pas de légitimer la superposition entre les deux phénomènes, ni non plus des expressions comme alphabétisation pour la/avec litéracie.
\end{abstract}

Mots-clés: Langue écrite. Litéracie. Alphabétisation.

\section{Introdução}

$\mathrm{E}$ ste artigo nasceu de um desconforto: o entendimento de que, por um lado, parece estar havendo uma ampliação desmedida do uso do termo letramento, estendido a esferas da convivência social nas quais o signo verbal escrito não se faz presente ou não é prevalecente; e, por outro lado, em um movimento oposto, parece ocorrer uma circunscrição desse mesmo uso, concebido à luz de perspectivas cognitivistas internalistas ${ }^{1}$ de língua escrita.

O que é de fato letramento? Penso que, após as discussões de natureza etnográfica e antropológica havidas no decorrer da década de 1980 - de que são exemplos especialmente significativos Heath (1982) e Street (1984) -, as quais, sob vários aspectos, motivaram o neologismo no Brasil, ${ }^{2}$ letramento delineou-se como um conceito intrinsecamente associado à concepção de escrita como prática social e como processo cultural. O conjunto de estudos empreendido desde então, quer no Brasil com nomes como Magda Soares, Leda Verdiani Tfouni, Angela Kleiman e Roxane Rojo, quer no exterior com contribuições de David Barton e James Paul Gee, entre outros tantos, sinaliza para a impossibilidade de discutir o fenômeno sem associá-lo a práticas socioculturais.

Se essa associação, por um lado, vem motivando um espectro mais amplo de possibilidades de focalizar o objeto de estudo língua escrita, por outro lado tem suscitado interpretações de natureza internalista que, em nome de salvaguardar as especificidades cognitivas do ato de ler, terminam por promover a assepsia da dimensão sociocultural do fenômeno. Discutir o desconforto que se elicia a partir dessas questões e as implicações educacionais correlatas é o objetivo deste artigo. 


\section{Um excessivo alargamento de fronteiras do conceito?}

É comum, hoje, o trânsito de expressões como letramento digital, letramento matemático e, em algumas instâncias, letramento musical ou artístico. Entendo que subjaz a esses usos uma das propriedades do fenômeno tal qual se erigiu em se tratando da língua escrita: a dimensão social, os contornos de cidadania, a legitimidade de lugares culturais implicados na construção do conceito de letramento. Importa, no entanto, a consideração de que letramento necessariamente implica vinculação com o signo verbal escrito, condição para que se fale de práticas de letramento ou de eventos de letramento, conceitos precisados por Heath (1982), Street (1988), Barton (1994), Hamilton (2000).

Entendo que Gee (2004) deu uma substantiva contribuição para os estudos sobre a língua escrita ao sugerir, em se tratando da classificação dessa modalidade de língua, a ruptura da dicotomia entre processos naturais e processos que demandam ensino. Para ele, a escrita precisa ser vista como um processo cultural: não é adquirida como propriedade da espécie, tal qual a fala, tampouco é produto da artificialidade do ensino, tal qual a aprendizagem da física. A escrita, para o autor, é um processo cultural, a exigir, sim, um mestre, mas, por ser parte do cotidiano da convivência humana, implica um aprendizado que se dá também em condições naturalísticas e não somente na sistematicidade da escolarização formal, tal qual o que se processa com conhecimentos enciclopédicos de um modo geral. Assim, a dicotomia aquisição $X$ aprendizagem estaria a carecer de um nível intermediário de classificação, a nosso ver, aprendizagem naturalística.

Essa argumentação de Gee (2004) remete aos achados de Bernard Lahire, documentados, sobretudo, na obra Sucesso escolar nos meios populares (1995), em que esse estudioso descreve magistralmente implicações do capital cultural familiar na apropriação, por parte da criança, entre outros conhecimentos, da língua escrita. Parece notório que, havendo a possibilidade de estabelecer relações intersubjetivas com familiares ou aparentados que façam uso efetivo da escrita, será facilitado à criança o domínio dessa modalidade da língua como instrumento de interação social. Se, em lugar do capital cultural de Bourdieu e Passeron (1975), a que faz remissão Lahire (1995), evocarmos Vigostki (2000[1984]) e suas teorizações sobre relações entre intersubjetividade e intrassubjetividade, poderemos considerar que, em havendo um mediador mais experiente que interaja com a criança no que respeita aos usos da escrita, a zona de desenvolvimento imediato dessa criança haverá de facultar-lhe a ressignificação de sua zona de desenvolvimento real.

Vale, nesta discussão, remeter a Mendes (2009) e à proposta de microcultura grafocêntrica que se elicia de seus estudos, ou seja, as configurações do entorno familiar e escolar de que toma parte a criança são substantivamente relevantes na 
apropriação de informações sobre a escrita. Parece fato que crianças inseridas em famílias em que prevalecem eventos de letramento de toda sorte e em alta incidência estão submetidas a um processo naturalístico de aprendizagem das funções sociais a que a escrita se presta e de como essa mesma escrita se configura para atender a tais funções.

Advogo, aqui, em favor de, tal qual propõe Gee (2004), conceber a aprendizagem da escrita, e, por via de consequência, seu uso, como um processo cultural. Agir assim supõe conferir ao estudo do fenômeno do letramento uma dimensão notoriamente vinculada a questões de cidadania, de identidade cultural, de mobilidade social. Essas implicações, no entanto, no meu modo de ver, não autorizam uma expansão desmedida do uso do termo letramento para instâncias diversas em que o signo verbal escrito não esteja presente ou não seja prevalecente. Pelo bem ou pelo mal, letramento tem implicações com littera, ou seja, requer necessariamente a presença da língua escrita.

Assim, suponho que o uso do termo na expressão letramento digital deva ser reavaliado, dado que as mídias digitais, por sua natureza configuracional, não se constituem de signos verbais escritos tão somente, revelando uma dimensão semiótica mais ampla. Parece residir, na subjacência desse uso, a preocupação com a (ina)acessibilidade dos sujeitos a essas mídias; logo, suponho que a migração do termo para essa área decorra da propriedade de sentido cidadania - ou significados correlatos - implícita em letramento. Essa propriedade, no entanto, não parece autorizar esse tipo de espraiamento do termo, sobretudo se considerarmos que a (ina)acessibilidade aos meios digitais decorre muito mais de questões de apropriação objetal e de operações procedimentais de uso das máquinas do que propriamente das habilidades de uso da língua escrita. O que esse universo suscita, a meu ver, são eventos de letramento - o que retomarei à frente - e não um fenômeno à parte, o letramento digital.

Em se tratando de ocorrências como letramento matemático, letramento musical, etc., a impropriedade parece residir no fato sabido de que se trata de semioses distintas e, nesses universos, ainda que o signo verbal escrito esteja presente, não é prevalecente na constituição dos processos. Assim, parecem louváveis os propósitos que movem o uso do termo nessas instâncias, mas esse comportamento seguramente compromete a precisão do conceito e, ao fazê-lo, incide sobre sua relevância.

Pode parecer incoerência conceber letramento sob uma perspectiva sociocultural e histórica, advogando em favor de se tomar a língua escrita como processo cultural e, ao mesmo tempo, depor contrariamente à expansão fecunda do uso do termo letramento, afinal, se o plano sociocultural e histórico está implicado, as fronteiras não poderiam ser assim expandidas? Importa seguramente que os limites 
conceituais do fenômeno sejam minimamente delineados, sob pena da perda da precisão desse mesmo fenômeno, sobretudo se considerarmos que, nesse processo de expansão, ao que parece, a questão-mor implicada no conceito de letramento, ou seja, a língua escrita, esteja flagrantemente secundarizada, o que coloca em risco sua condição de inerentemente constitutiva desse mesmo fenômeno. Nesse caso, a nomeação do fenômeno em si mesma prescindiria do morfema lexical que o constitui e, por consequência, estaria desfeita a necessidade do neologismo.

\section{A contraface: um excessivo estreitamento de fronteiras do fenômeno?}

Movimento oposto se evidencia em discussões no âmbito da psicolinguística aplicada, território em que parece haver um zelo exacerbado em relação à vinculação do fenômeno aos atos de ler e escrever em seu sentido estrito, o que decorre, em meu entendimento, da assepsia do conteúdo sociocultural de letramento.

A não aceitação do uso do termo letramento para designar, por exemplo, comportamentos que Heath (1982) descreve, especialmente o ato de, de posse de livros, ler/contar histórias para as crianças antes de dormir, ${ }^{3}$ tanto quanto a não aceitação do uso do termo para designar atitudes de analfabetos que vivem em sociedades grafocêntricas, a exemplo de tomar o ônibus a partir da escrita que o particulariza mesmo sem conseguir decodificar tal imagem, ${ }^{4}$ sinalizam para o estreitamento dessa concepção.

É notório que o ato de ler, tomado na circunscrição do processamento cognitivo, implica, como quer Morais (1996), a existência de língua escrita e a capacidade de leitura, entendida como o conjunto de processos cognitivos específicos desse mesmo ato de ler, o que remete à indispensabilidade da decodificação. Trata-se, a meu ver, de um sentido estrito de leitura. Se evocarmos considerações de Paulo Freire (1992) (das quais tem se apropriado o discurso do senso comum), sobre a precedência da leitura de mundo em relação à leitura da palavra, ${ }^{5}$ seguramente estaremos tratando de leitura em sentido lato, o que, em minha compreensão não constitui equívoco, desde que feita a devida salvaguarda acerca da natureza da concepção subjacente ao conceito de leitura de mundo: uma concepção de leitura em sentido lato. Essas concepções de Freire, no entanto, em meu entendimento, foram embrionárias para o surgimento do conceito de letramento, mas, na "leitura de mundo" não está implicado o fenômeno do letramento em si mesmo, a menos que essa "leitura de mundo" faça remissão a atributos grafocêntricos desse mesmo mundo, o que não parece ser o caso.

Neste sentido, entendo que, mais do que uma impropriedade, revelam-se uma impossibilidade remissões a letramento que tragam consigo um viés cognitivista internalista. $\mathrm{O}$ neologismo surgiu para dar conta de um espectro mais amplo do 
universo da leitura e da escrita, com conotações sociais, culturais e históricas, o que já advertia Tfouni (1995), ao distinguir letramento de alfabetização, concebendo aquele em seus contornos sócio-histórico-culturais e esta em seus contornos individuais.

Esse meu entendimento, porém, sob nenhum aspecto desconsidera a compreensão legítima de leitura como processamento cognitivo individual, que implica necessariamente decodificação e, hoje, à luz das neurociências, conforme Dehaene (2007), configura-se como um intrincado processo que envolve a área occipito-temporal-ventral-esquerda do cérebro; logo, implica a via fonológica inerente às relações grafêmico-fonêmicas constitutivas do processo de decodificação.

O desconforto decorre da compreensão de que se trata de olhares distintos sobre a leitura, cada qual fruto de uma forma distinta de conceber o objeto. Street (1984) já apontava para um desdobramento do conceito em questão, o que foi amplamente descrito por esse autor como modelo autônomo de letramento e modelo ideológico de letramento. Assim, atos como, de posse de livros, contar histórias para crianças antes de dormir (Heath, 1982) e haver-se em uma sociedade grafocêntrica, tomando parte de eventos de letramento (Heath, 1982; Street, 1988; Barton, 1994), mesmo sob a condição de analfabetismo (Soares, 1998), só podem ser concebidos sob a égide do fenômeno do letramento por aqueles que sustentam uma concepção convergente com o modelo ideológico (Street, 1984), ou seja, entendem letramento como conjunto de práticas de uso social da escrita - o que me parece muito próximo do pensamento de Freire (1992).

Partidários do modelo autônomo - sob vários aspectos visões cognitivistas internalistas -, que dicotomizam oralidade e escrita, tendem a condenar o uso do termo letramento para atividades dessa natureza e, não raro, tangenciam a precisão de estudos como o de Heath (1982), tomando-os como sinônimo de que a atividade da narrativa, por exemplo, estaria sendo postulada como evento de letramento. Um dos argumentos para tal contraposição é que a narrativa oral tem lugar cativo mesmo em sociedades ágrafas. Evidentemente apresentar um argumento com esse conteúdo para contrapor-se a estudos como o de Heath tem subjacente a ignorância ou a denegação propositada acerca das particularidades e das conclusões desse mesmo estudo, amplamente conhecido pelos interessados neste tema.

O zelo de visões cognitivistas internalistas na concepção do que seja ou do que não seja letramento parece remeter a sua forma estrita de conceber a leitura e a escrita, o que é coerente com as bases epistemológicas que sustentam tais estudos e, por via de consequência, em meu entendimento, também coerente com o modelo autônomo de letramento de que trata Street (1984). Essas visões não têm compromisso com a sociocognição, estando, pois, desincumbidas de pensar a escrita como processo sociocultural e histórico. Essa condição, no entanto, não lhes autoriza tratar como equívoco a compreensão de letramento sob o vértice do modelo ideológico. 
Por que o desconforto com essa visão estrita, ainda que a reconheça como legítima em sua lógica? Tal desconforto advém do entendimento de que essa circunscrição contribui para colocar em xeque a relevância do conceito. Se é para conceber letramento como práticas de leitura amplamente descritas ao longo de cerca de 50 anos de estudos cognitivistas internalistas (Smith, 1988; Morais, 1996; Van Dijk \& Kintsch, 1983; entre outros), não me parece haver razão para o neologismo letramento. Entendo que o verbete de Houaiss (2001, p. 1.747) que define letramento como "conjunto de práticas que denotam a capacidade de uso de diferentes tipos de material escrito" instaura esse olhar de neologismo sobre o termo e, se assim é, o processo que culmina com tal neologismo teve origem em novas demandas de significação; logo, os 50 anos da visão cognitivista internalista seguramente não responderam a essa demanda que se criou pelo conceito.

Assim, circunscrever o uso do termo, condenando como impropriedades interpretações que tenham um escopo sociocultural e histórico e que remetam à microcultura grafocêntrica (ou não grafocêntrica) dos entornos em que se inserem os sujeitos constitui, a meu ver, risco para que a efetiva relevância do conceito seja de fato compreendida pela sociedade. Entendo que visões cognitivistas internalistas prescindam desse conceito para suas teorizações; trata-se, ao que parece, de um território de sociocognição incompatível com seus postulados. Haveria razão, pois, para remissão a ele em seus estudos? Fica a questão.

\section{Consequências dessas turbulências de limitação conceitual no dia a dia dos envolvidos com a escola}

Entendo que essas oscilações de fronteiras comprometem o ato de delinear o que seja de fato letramento. Esta seria apenas uma discussão de âmbito teórico caso não tivesse as implicações que suponho que tenha na realidade escolar. São comuns, em congressos, palestras e eventos afins, perguntas de educadores sobre as diferenças entre alfabetização e letramento. E, se essas perguntas persistem, parece notório que derivem da falta de clareza sobre o tema.

Tfouni (1995, p. 20) tratou dessa questão com refinamento ao escrever: "Enquanto a alfabetização se ocupa da aquisição da escrita por um indivíduo, ou grupo de indivíduos, o letramento focaliza os aspectos sócio-históricos da aquisição de um sistema escrito por uma sociedade". Penso que essa compreensão precisa grassar e ganhar terreno em publicações diversas. Entendo que a autora dá conta de que o conceito de letramento se presta a funções e papéis distintos da alfabetização, no entanto não parece ser essa a compreensão que vigora nas escolas.

Emília Ferreiro, em entrevista para a revista Nova Escola (maio de 2003), registra: 
Há algum tempo, descobriram no Brasil que se podia usar a expressão letramento. E o que aconteceu com a alfabetização? Virou sinônimo de decodificação. Letramento passou a ser o estar em contato com distintos tipos de texto, o compreender o que se lê. Isso é um retrocesso. Eu me nego a aceitar um período de decodificação prévio àquele em que se passa a perceber a função social do texto. Acreditar nisso é dar razão à velha consciência fonológica.

Comungo com Ferreiro essa insurreição, mas o faço com ressalvas. De fato, se o conceito for assim compreendido, a autora tem sobejas razões para se insurgir a ele. Entendo, no entanto, que não é essa a compreensão de letramento que motivou o neologismo no Brasil. Aliás, penso que nunca a co-ocorrência dos conceitos letramento e alfabetização foi tão necessária. Devo ser mais precisa quanto a essa necessidade.

Da leitura dos textos seminais sobre letramento - Brian Street, Shirley Heath, Harvey Graff, entre outros - parece emergir a compreensão de que letramento precisa ser concebido à luz das particularidades socioculturais e econômicas dos entornos mais grafocêntricos ou menos grafocêntricos nos quais se inserem os sujeitos em sua materialidade histórica. Bernard Lahire tem chamado atenção para a necessidade de uma sociologia individual, o que, em se tratando de práticas de uso social da escrita, tem, em meu entendimento, crescente importância.

Possivelmente a língua escrita nunca tenha estado tão presente e nunca tenha sido tão importante na vida dos sujeitos. Entrar em uma agência bancária, no Brasil, implica, hoje, mover-se tendo a escrita como guia - desde a obtenção da senha para o atendimento -, tanto quanto deslocar-se por um grande aeroporto internacional como o de Madri, no qual não há chamadas orais para voos, entre outras particularidades; ou, ainda, perambular por Lisboa em veículos públicos eletrônicos, nos quais, da compra do bilhete ao acompanhamento das estações de embarque e desembarque, tudo é regido pela escrita. Tais ambientes, sob vários aspectos, em nome da automação, vêm prescindindo da oralidade em um processo de flagrante sobrevalorização do ato de ler e construir sentidos. Demandam esses mesmos ambientes um conjunto de ações fruto de decisões decorrentes do ato de ler: para aonde ir, a quem se dirigir, o que fazer, etc. são comportamentos guiados pela leitura de informações em diferentes portadores automáticos de texto.

Trata-se, em meu entendimento, de uma propriedade das sociedades atuais que ganha contornos mais intensos a cada novo ano, instigada, em larga medida, pelos avanços da automação. E, se essa sociedade se torna crescentemente mais centrada na escrita, naturalmente, ao que parece, irão recrudescer processos de exclusão, motivados por um domínio menor dessa mesma escrita. Outra propriedade aqui implicada é o fato de que questões procedimentais de mobilidade social começam a requerer maior refinamento nesse domínio: tomemos como exemplo a habilidade de haver-se na leitura de diferentes menus, processo do qual depende o uso de infinitos 
recursos da tecnologia, desde telefones celulares até terminais bancários eletrônicos, dos quais depende grande parte da população mundial contemporânea.

Se isso é verdadeiro, como alfabetizar sujeitos sem considerar, como quer Lahire (1995), a dimensão sociológica individual desses mesmos sujeitos? É plenamente sabido que, em razão de questões socioeconômicas, há contingentes de crianças alijados de uma série de eventos de letramento, ao passo que um grupo expressivo delas tende a enfronhar-se paulatinamente mais em eventos de letramento de grande variabilidade e complexidade, tais quais os intrincados programas de computadores para diferentes finalidades, tanto quanto televisores e aparelhos domésticos dotados de tais menus escritos, cuja operacionalização demanda domínio crescentemente mais complexo dos processos operacionais escritos. Isso traz consigo demandas conceituais dia a dia mais variadas, dado que, com a explosão da automação e da tecnologia, vem a reboque uma sobrecarga conceitual de que nem todos os sujeitos, em razão de sua materialidade sociocultural e econômica, conseguem se apropriar. Como lidar, por exemplo, com um comando intitulado read from file, determinante para que o indivíduo se mova em vários softwares atuais? Tais comandos multiplicam-se e diversificam-se diariamente, exigindo dos sujeitos uma crescente apropriação conceitual intrinsecamente ligada aos usos da escrita.

Então, mais uma vez, em se tratando de alfabetização, poderão prevalecer, nesse contexto atual, embates tão históricos quanto pendulares, entre métodos sintéticos e analíticos, como se os alfabetizandos pudessem ser tomados em uma massa única e amorfa? Parece certo, como tem mostrado Dehaene (2007) - no Brasil, sob as lentes de Scliar-Cabral -, que o ato de ler, situado na região occipito-temporal-ventral-esquerda, implica via fonológica; logo, não haveria mais o que discutir acerca da necessidade de se proceder ou não a relações grafêmico-fonêmicas e fonêmicografêmicas por ocasião do ato de alfabetizar. Isso significa que o embate pendular jurássico estaria definitivamente sepultado?

Paralelamente a isso, no entanto, é sabido que alfabetizadores formados por cursos de Pedagogia e Letras da modernidade, segundo hipótese que carece de testagem em diferentes regiões do país, tendem a não dominar suficientemente construtos teóricos que lhes facultem uma ação didático-metodológica consequente no ato de alfabetizar. Dizendo de outro modo, parece ser fato que grande parte dos alfabetizadores, por exemplo, não domina particularidades do sistema alfabético do português do Brasil, tão detalhadamente descrito e estudado por Scliar-Cabral (2003). Outra questão que não parece ser de domínio efetivo de grande parte desses profissionais são os postulados teórico-epistemológicos de aprendizagem que norteiam escolhas metodológicas e ações docentes, o que levaria muitos alfabetizadores a se intitularem piagetianos ou vigotskianos sem de fato conhecerem o pensamento desses autores em suas especificidades. 
Essas suposições justificariam, por exemplo, a apologia da necessidade de oferecimento de boas cartilhas para tais profissionais, já que estariam limitados por um desconhecimento crônico em se tratando de teorias relevantes em sua ação, sem mencionar a circunscrição de tempo com que contariam para o ato de planejar suas aulas. Todo esse discurso, porém, a meu ver, é sustentado por uma concepção de alfabetização destituída dos contornos socioculturais, econômicos e históricos em que se situam os sujeitos artífices desses processos, contornos tão caros ao conceito do letramento. É como se estivéssemos tratando de um fenômeno em que houvesse assepsia da materialidade histórica dos sujeitos. Aqui, a meu ver, o conceito de letramento é fundamental e se distingue de alfabetização visivelmente.

Se considerarmos o fenômeno do letramento tal quais os estudos seminais já mencionados nos levam a compreendê-lo, trata-se de um conceito essencial na co-ocorrência com a alfabetização e que não se sobrepõe a ela; ao contrário, que é continente e a tem como um de seus conteúdos. Isso porque letramento seria um fenômeno iluminador da natureza desse processo, que necessariamente é concebido em um entorno sociocultural ou em outro.

Devo ser mais específica: alfabetizar uma criança inserida em um entorno em que a escrita é flagrantemente usada para diferentes fins - a criança que passa grande parte de seu tempo lidando com menus eletrônicos, por exemplo - e alfabetizar uma criança que vive em uma comunidade onde não há nem mesmo placas indicativas de lojas ou de mobilidade no trânsito parece requerer do profissional uma compreensão distinta do ato de alfabetizar por uma razão óbvia: a presença da escrita difere substantivamente nesses entornos e, por via de consequência, o que as crianças sabem sobre a escrita e o que fazem com ela é muito distinto.

Uma das grandes contribuições de Emília Ferreiro, a meu ver, foi mostrar que as crianças trazem para a escola conhecimentos sobre a língua escrita, quer sejam tais conhecimentos mais precisos e específicos ou mais genéricos. O que Ferreiro não discutiu - e o fenômeno do letramento propõe-se a fazer - são as razões socioculturais e econômicas que justificam essa maior ou menor precisão. Logo, trata-se de uma contribuição que não pode ser denegada sob a alegação de que o construtivismo de Ferreiro não deu certo. Primeiramente, importa saber onde, se e por que não deu certo, procurando em evidências empíricas cientificamente analisadas a veracidade dessas suposições, além do que é um já-dito a compreensão de que a autora não propôs um método; logo, não poderia ter dado certo o que não houve de fato.

Eis o ponto em que o conceito de letramento mais uma vez se mostra distinto do conceito de alfabetização e se faz relevante. O universo do ato de alfabetizar é múltiplo e, em que pese a possibilidade de essa minha argumentação ser taxada de relativismo, entendo que o que explica essa multiplicidade é o fenômeno do letramento, o 
qual, portanto, deve iluminar as decisões sobre o ato de alfabetizar, porque é sensível à sociologia individual de que trata Lahire (1995) e às especificidades dos diferentes entornos culturais em que se situam os protagonistas do ato de alfabetizar.

Da denegação da importância do fenômeno do letramento na iluminação do fenômeno da alfabetização decorre, por exemplo, a condenação de o processo de alfabetização começar pelo nome das letras. Scliar-Cabral (2003) tem sobejas razões, de natureza cognitiva e linguístico-sistêmica, para condenar encaminhamentos dessa ordem, afinal como mostra indefectivelmente a autora, um grafema pode ter valores distintos no sistema alfabético; logo, iniciar pelo conhecimento do nome das letras pode constituir um fator sensivelmente complicador para as crianças.

Minha ressalva, no entanto, seguindo a lógica que perpassa este artigo, é: esse pode ser um óbice para crianças de alguns entornos socioculturais, mas tal denegação do nome das letras no processo inicial pode não fazer sentido em outros entornos, nos quais as crianças, desde a mais tenra idade, são instigadas por familiares a identificar as letras pelo nome e o fazem brilhante e efusivamente sem, ao que se tem notícia, traumas no aprendizado posterior da escrita. Mais uma vez, advogo em favor do aprendizado da escrita como o processo cultural de que fala Gee (2004).

Essa dimensão remete ao capital cultural de que tratam Bourdieu e Passeron (1975) e que proponho ler pelas relações intersubjetivas mencionadas por Vigotski (2000 [1984]), e parece ser determinante nas escolhas que os alfabetizadores têm de fazer para ensinar a língua escrita a seus alunos. De novo o fenômeno do letramento: quem são os alunos a alfabetizar? O que sabem sobre a língua escrita? O que fazem com a língua escrita? Que valor atribuem a ela? Talvez valesse, aqui, o conceito de capital axiológico porque, tal qual mostram Lahire (1995) e Mendes (2009), não raro as famílias não dispõem de capital cultural sobre a escrita para socializarem com as crianças, mas ofertam a elas um capital axiológico sobre a escrita, instigando-as a dominarem essa modalidade, não pelo conhecimento de que dispõem dela, mas pelo valor que atribuem a ela, embora não a dominem.

Outra questão que parece ter implicações substantivas nesta discussão é o desmembramento do ano para alfabetizar em várias etapas, havendo sistemas, tais qual a Rede Municipal de Ensino de Florianópolis, que mantêm blocos de alfabetização; aqui, o Bloco Inicial de Alfabetização (BIA), composto por três anos de escolarização. Nesses casos, como fica o processo? Esse desdobramento está a suscitar pesquisas das quais deva emergir um novo conceito para o fenômeno alfabetização, mais uma vez demandando a consideração do fenômeno do letramento.

Um último ponto que reputo fundamental nesta discussão são as expressões alfabetização para o letramento, alfabetização com letramento, alfabetizar letrando e congêneres. Entendo tais expressões como fruto de equívocos na compreensão do que 
seja o fenômeno. Vejo o processo de alfabetização como conteúdo do fenômeno do letramento - um de seus conteúdos -, conteúdo entendido, aqui, como parte de um todo maior. Logo, a direcionalidade alfabetização para o letramento ou o movimento alfabetizar letrando, em minha percepção, são o combustível para a insurreição de Ferreiro (2003): só me parece possível esse tipo de expressão se a alfabetização for tomada como sinônimo de codificação/decodificação. Do contrário, não há razões para essa justaposição, porque a alfabetização seria concebida como uma das múltiplas formas que assume a dinamicidade do processo de letramento, tendo a sua especificidade: instrução formal, sistemática, que foca na natureza linguístico-sistêmica da língua escrita tanto quanto em sua natureza funcional. Aceitar isso requer compreender a alfabetização como um conceito legítimo que implica o domínio do sistema alfabético para usar a escrita na sociedade, não podendo circunscrever-se a questões formais apenas. Essa é uma discussão, a meu ver, esgotada.

Entretanto, se o vértice que perpassa este artigo for aceito, não há razões para tais expressões porque o letramento seria concebido como um fenômeno maior, à luz do qual o processo de alfabetização seria delineado, isso porque o fenômeno do letramento permitiria ao alfabetizador conhecer o que o entorno social do qual seus alfabetizandos são parte faz com a escrita, isto é, que práticas e eventos de letramento (Street, 1988; Barton, 1994; Hamilton, 2000) caracterizam tal entorno. Assim, a partir dessa compreensão, esse alfabetizador delinearia o processo a ser empreendido com seus alunos, o que nenhuma cartilha, por mais predicados de notoriedade e precisão teóricas tenha, poderá uniformizar.

\section{Considerações finais}

Penso que, com letramento, esteja acontecendo o que parece ter se dado com outros fenômenos do campo da linguagem, a exemplo de temas como gramática normativa e tipologias textuais. Concebo que a esses casos se possa aplicar a teoria da curvatura da vara, de Lênin, já que se trata de questões que foram objeto de intensa discussão no que respeita ao universo da escola, sem terem sido, ao que parece, devidamente compreendidas pelos educadores. A gramática normativa foi severamente alvejada a partir de discussões pertinentes e legítimas oriundas do campo da sociolinguística, assim como as tipologias textuais foram polemizadas com base em também legítimas e pertinentes teorizações sobre gênero. Ocorre que, ao que parece, a essência dessas teorizações não chegou aos professores de modo geral, exceto anúncios pontuais, disseminados em cursos de breve extensão que tematizaram e vêm tematizando o conteúdo dessas polêmicas. Isso, entendo, tem se dado com o conceito de letramento. Poucos são os educadores que têm tido acesso aos estudos de Brian Street, David Barton, Harvey Graff e afins, em sua origem. Às vezes esse acesso se limita a escritos de 
segunda mão que se reportam, nem sempre com precisão, ao pensamento de Angela Kleiman e Magda Soares, por exemplo.

Se isso é fato, parece compreensível a existência da curvatura da vara. Educadores tendem a ser temporariamente convencidos a uma mudança de postura didático-pedagógica, sem, no entanto, haver a devida apropriação conceitual acerca das razões pelas quais as mudanças são propostas. Assim, com base, na maioria das vezes, em aportes teóricos frágeis ou lacunares, educadores tendem a assimilar, em suas falas e em suas ações, conceitos e teorias novos sem a devida segurança e solidez. Daí para a retomada de posturas antigas parece ser apenas um passo. Não é à toa que assistimos a movimentos de retorno (se é que um dia houve de fato o abandono) de posturas gramaticais normativistas e de abordagens textuais sistêmicas em muitas escolas.

Com as discussões de letramento, parece dar-se o mesmo. É possível que o conceito tenha chegado à maior parte das escolas tão somente como um anúncio do que propunham seus mentores, o que provavelmente se agravou com esse movimento de alargamento versus circunscrição de fronteiras do conceito, alardeado por teóricos de tendências diversas. Imagino que os professores, por algum tempo ainda, deverão perguntar: Quais as diferenças entre alfabetização e letramento?

\section{Notas}

1. Por internalistas, para as finalidades deste artigo, entendo o foco em processamentos cognitivos tomados em uma abordagem que não considera a dimensão social da cognição.

2. Importa, evidentemente, considerar as contribuições de Paulo Freire para que esse processo fosse gestado.

3. Uma atividade cuja natureza requer a existência de livros ou remete necessariamente a eles.

4. Isso se dá tal qual sugere Soares (1998).

5. Importa registrar que, em Morais (1996, p. 111), parece estar implícita uma crítica a essa concepção freiriana, quando aquele autor escreve: "(...) o ponto de vista de um autor que, numa conferência sobre leitura, julgou útil propor que, 'no seu sentido mais amplo, a leitura é o processo de interpretação dos estímulos sensoriais'. Entretanto, é fácil perceber que essa definição de leitura é, ao mesmo tempo, falsa e perniciosa".

\section{Referências}

BARTON, D. Literacy: an introduction to the ecology of written language. Oxford: Blackweell, 1994.

BOURDIEU, P.; PASSERON, J.C. A reprodução. Rio de Janeiro: Francisco Alves, 1975.

DEHAENE, S. Les neurones de la lecture. Paris: Odile Jacob, 2007. 
FERREIRO, E. Entrevista à revista Nova Escola. Nova Escola, São Paulo, v. 18, n. 162, abr./ maio 2003.

FREIRE, P. A importância do ato de ler. São Paulo: Cortez, 1992.

GEE, P.J. Situated language and learning: a critique of traditional schooling. London: Routledge, 2004.

GRAFF, H. The labyrinths of literacy. London: Falmer, 1987.

HAMILTON, M. Expanding the new literacy studies: using photographs to explore literacy as social practice. In: BARTON, D.; HAMILTON, M.; IVANIC, R. (Org.). Situated literacies. London: Routledge, 2000. p. 16-34.

HEATH, S.B. What no bedtime story means: narrative skills at home and school. Language in Society, Cambridge, v. 11, p. 49-77, 1982.

HOUAISS, A. Dicionário da língua portuguesa. São Paulo: Objetiva, 2001.

KLEIMAN, A. (Org.). Os significados do letramento: uma nova perspectiva sobre a prática social da escrita. Campinas: Mercado de Letras, 1995.

LAHIRE, B. O sucesso escolar nos meios populares. São Paulo: Ática, 1995.

MENDES, A. Implicações da cultura grafocêntrica na apropriação da escrita e da leitura em dois diferentes contextos. 2009. Tese (Doutorado em Educação) - Universidade de São Paulo, São Paulo.

MORAIS, J. A arte de ler. São Paulo: Unesp, 1996.

SCLIAR-CABRAL, L. Princípios do sistema alfabético do português do Brasil. São Paulo: Contexto, 2003.

SCRIBNER, S.; COLE, M. The psychology of literacy. Cambridge: Cambridge University, 1981.

SMITH, F. Compreendendo a leitura: uma análise psicolinguística da leitura e do aprender a ler. Porto Alegre: Artes Médicas, 1988.

SOARES, M.B. Letramento: um tema em três gêneros. Belo Horizonte: Autêntica, 1998.

STREET, B. Literacy in theory and practice. Cambridge: Cambridge University, 1984.

STREET, B. Literacy practices and literacy myths. In: SALJO, R. (Org.). The written world: studies in literacy thought and action. Nova York: Springer, 1988. p. 59-72.

TFOUNI, L.V. Letramento e alfabetização. São Paulo: Cortez, 1995. 
VAN DIJK, T.; KINTSCH, W. Strategies of discourse comprehension. Nova York: Academic, 1983.

VIGOTSKI, L. A formação social da mente. São Paulo: Martins Fontes, 2000 [1984].

Recebido em 15 de julho de 2010.

Aprovado em 17 de maio de 2011. 